\title{
Perspectives of Parents on Communication Challenges Faced in Educating Learners with Hearing Impairments
}

\author{
Rosemary Ogada \\ School of Education, Rongo University, PO box 103-40404, Rongo, Kenya
}

\begin{abstract}
Focusing on Education Policy for Deaf Children, the World Federation of the Deaf (WFD, 2016) postulated that children with HI have a right to full access to quality education and that since persons with hearing impairments (HI) are mainly visual, sign language and visual strategies must be availed to learners with $\mathrm{HI}$ as a birthright. This may be interpreted to mean that if quality education is not availed to learners with $\mathrm{HI}$ using visual strategies and in sign language, the policies laid down by WFD would have been contravened. It can also be implied that sign language needs to be availed to learners with $\mathrm{HI}$ at home with parents, siblings and care givers where they grow and learn before going to school. The purpose of this study was therefore to establish the perspectives of parents on communication challenges faced in educating learners with hearing impairments in. This study adopted a case study research design using a qualitative research approach and was informed by the Social Model of Disability as propagated by Union of Physically Impaired Against Segregation (UPIAS) (1976). The objective of the study was to establish the perspectives of parents on communication challenges faced in educating learners with hearing impairments. The target population was 177 comprising 150 parents of learners with hearing impairments, 26 teachers and 1 Quality Assurance and Standards Officer. The study employed purposive sampling technique to sample 30 parents and 13 teachers while saturated sampling technique was used to for 1 Quality Assurance and Standards Officer (QUASO). Data was collected by use of interview schedules, focus group discussion guides and document analysis guides. Trustworthiness was established by use of detailed report of the process within the study, member checks and overlapping methods. Data was analyzed using thematic analysis technique as proposed by Braun and Clarke (2006). The study established that most parents of learners with hearing impairments held the view that sign language was too difficult to learn at their age though they expected the school and the government to facilitate sign language trainings for them. This study concluded that communication between parents and their children was ineffective because parents viewed themselves as unable to learn sign language and communication between parents and the school was ineffective because most parents viewed the teachers as disorganized in the way they communicated with parents.
\end{abstract}

Keywords: Hearing impairments, communication, parents, learners, challenges, educating learners with HI DOI: $10.7176 / \mathrm{JEP} / 10-3-04$

\section{Introduction}

Many times communication in education for the $\mathrm{HI}$ is viewed as limited to learning and using Sign language so as to communicate with the children. Whereas this may form an important part of communication, it is also true that there needs to exist good communication between the parents and the school. According to Scottish Government Publication (2005), Challenges in communication were classified into several categories; communication between parent and child, parent and school and between child and peers/siblings. Most parents had communication challenges with their children because of lack of a common mode of communication given their children used sign language which they had not learned. Scottish Government Publication (2005) also submitted that parents complained that the school was not giving enough information to them or giving information too late. As a result, parents often felt left out on a lot of information concerning the education of their children. This in turn frustrated the parents since they could not help their own children with school work (Scottish Government Publication, 2005).

In addition, research has shown that some of the communication challenges between parents and their children with HI are because parents would not learn sign language. According to Gray (2011), when parents of children with HI do not learn how to sign, children with HI lag behind in their cognitive development because of lack of a language of communication at home with parents and siblings. Gray (2011) goes further to explain that, a child who does not have a language of communication early in life, grows totally unaware of the ordinary things going on around them. It is not clear how parents of learners with HI perceive the necessity to learn to communicate with HI learners more effectively though communication is important to educational success for learners with $\mathrm{HI}$.

\section{Literature Review}

Some studies have shown that parents may need motivation in order to learn sign language. Kimberly (2010) carried out a study in the USA that aimed at understanding the motivation and needs of the target group when learning sign language. Interviews and Focus Group Discussions were carried out with eleven (11) parents of 
learners with HI who were purposely sampled. Parents had varied views towards learning sign language. Whereas some complained of stigma, lack of prior experience with deafness and American Sign Language being difficult, some treated sign language as a temporary language before oral English is acquired. The study found out that the primary motivation among parents for learning sign language was to communicate with their children.

In a report of the proceedings of the $4^{\text {th }}$ International Symposium on Bilingualism held in Arizona State University, U.S.A., Standley (2005) noted that there is need for learners with HI to have proficiency in a First Language by the time that they enter school and to develop communicative competence and literacy in the first language prior to acquiring literacy in a second language. The report revealed that children with HI from hearing families experienced significant language delay which was detrimental to their educational success. The Symposium recommended that in order to facilitate the acquisition of First Language, it would be necessary to introduce a professional who would provide intensive language instruction for the child with HI and their family and review the current role of the educational interpreter. Getting a professional to work with parents and their children with HI on learning a First Language may not be applicable in families in Kenya given the different cultural and economic contexts between U.S.A and Kenya.

In another study carried out in the USA and United Kingdom (Marschark, et al., 2012) on perspectives of children with HI, children without HI and their parents on socio-emotional and academic functioning in school, questionnaires were used to collect data from fifty four (54) children with HI and fifty four (54) hearing children. The study established that, learners with HI whose parents were also HI used sign language and were attending programs intended for the HI had improved social and academic functioning as a result of better communication between them and their parents. Effectiveness of communication at home was an indicator as to whether a child had a hearing parent or a parent with HI. The study concluded that social success among the HI was significantly influenced by whether parents were hearing or HI and whether child-parent communication involved sign language. The reviewed study therefore seems to imply that parents need to know the language their children should learn as a first language for success in education.

It is notable that the challenge of communication between parents and their children with HI does not only manifest in the parents' inability to learn and use signs but also in learners' lack of sign language skills. Disability and Development Partners (2011) compiled a report on Deaf Children in Burundi by interviewing ten (10) informants comprising of nine parents and one child minding other children. These were parents of ten (10) children with HI out of which seven were out of school and three were in school. The study found out that most parents communicated with their children with HI through gesture and sign language while a few parents said they did not know how to communicate. Seven parents whose children were not in school said neither them nor their children knew sign language but the three whose children were in school stated that their children were learning sign language and so communication was easier.

In Kenya, Kimu (2012) carried out a qualitative study with one thousand three hundred and seven $(1,307)$ teachers drawn from one hundred and forty one (141) public primary schools. The aim of the study was to understand and describe how parents and educators experience parental involvement from their own perspectives in public primary schools according to Epstein's typology of parental involvement. Data was collected by use of literature review, interviews, observations and focus group discussion methods. According to Epstein's typology, parental involvement included communicating with the school, decision making and collaborating with the community for the purposes of helping the learner. The study found out that, support services were limited by financial difficulties and teacher-parent meetings. Teacher-parent meetings are important forums for fostering communication between parents and teachers and enhancing learners' welfare. Therefore, parents' perspective may have an effect on learners' educational success.

Research (Adoyo, 2004), has proved that many children with HI have hearing parents calling for the communication gap between the learners and their parents to be narrowed and possibly closed. In order for this to be done, parents have an obligation to realize they have a role to play and then step out and play that role. In this study carried out in Kenya, Adoyo (2004) found out that out of 450 Children with HI, only 5(1.1\%) had Deaf parents while the rest 445 (98.9\%), had hearing parents. The focus of the study was on effects of Kenyan Sign Language and simultaneous communication on memory and comprehension. Hearing parents admitted communication difficulties with their children which they attributed to lack of knowledge in sign language. Parents' lack of or incompetence in sign language became a great challenge when they needed to communicate both academic and social values and decisions to their Children with HI. In addition, parents realized that they had a primary role to play in the education of their children which would be successful only if they learnt the language their children with hearing impairments could understand.

The reviewed studies have considered communication both at home and at school as being important for the success of learners with $\mathrm{HI}$ and those without HI from different perspectives. The current study sought to establish perspectives of parents on communication challenges. 


\section{Methodology}

This study employed case study design which sought to give detailed description of each unit in context and holistically. Case study was used to enable the researcher to analyze the unit of study in details within its context (Rule \& John, 2011; Bertram \& Christiansen, 2013; Yin, 2011). Case study data was gathered using different research methods such as, Interviews, Focus Group Discussions and Document Analysis (McLeod, 2008). According to Yin (2009), case study is an empirical inquiry method that investigates a contemporary phenomenon in depth and within its context. The data obtained was analyzed thematically (Braun and Clerke 2006).

\section{Findings}

The objective of the study was to establish the perspectives of parents on communication challenges faced in educating learners with HI. The study considered perspectives of parents on communication challenges at two levels; communication challenges between the parent and the learner and communication challenges between the parent and the school or teachers.

\subsection{Communication between the parent and the learner}

Results from interview with parents indicated that most parents found communication to be the greatest challenge in educating their children with HI. Many of the parents stated that they would have wished to communicate better with their children with HI but were hindered by lack of knowledge in sign language or opportunities to learn. One parent lamented;

I would have loved to learn and in fact, I had started. However, we have since moved to the village where there are no places for learning sign language and I forgotten most of what I learnt. The boarding school where the girl is has not done anything in assisting parents to learn sign language in order to make communication easier between us and the child. (IP07)

The respondent IP07 indicated his willingness to learn sign language but services were not readily available. He has also indicated that he had learnt a little sign language when their child was in primary school because they were living in a town where were services and forums for training were available and the schools also made effort to assist parents acquire basic sign language.

Most parents confessed having difficulties communicating to their children very basic concepts. Parents also admitted having problems carrying out discipline on their children because they had no common language of communication. The following excerpt communicates one parent's sentiments:

I want the child to get exactly what I am saying, the way I am saying it. Like some day I was really angry about her performance in Geography and the teacher was a very polite one and I could tell that he was putting my points too politely. I was so disappointed yet there was nothing I could do. (IP09)

According to respondent IP09, academic counseling sessions were some of the areas in which many parents felt inadequate because they were unable to articulate what they really wanted to the child directly. They always had to talk through the teacher and get feedback through the same. Some parents felt that there was something lost through interpretation that they could not handle

The parents mentioned that sometimes they solicited the assistance of the younger siblings who had acquired sign language to help in interpretation. One mother said:

There are a lot of things I wish I could communicate to my daughter about teenage and life in school. I cannot say some things before her brothers and sisters for fear of embarrassing her. I am trying to learn more signs...I think I am old because am not learning fast enough. (IP011)

From this response, the mothers still felt that there were many things they missed out in communicating to the daughters about teenage and school life that they could not say when the brothers were interpreting. The mothers felt that privacy was a delicate matter when one had to use an interpreter. However, concerning learning sign language, some parents had the view that they were too old to learn. This may mean that though they dreaded using interpreters, they had to continue using them or risk not communicating with their children at all.

Most of the parents who found communication in sign language difficult indicated they resorted to writing. Writing was helpful but time consuming and some element of communication, such as the body language, was lost in the process. Writing also made communication become such a formal exercise since one always had to stop what they were doing, look for a pen and a paper before communication would commence. In addition, parents were concerned that writing reduced communication to short questions and answers. As a result parents observed that meaningful conversation was impossible. Many parents admitted feeling guilty when their children with HI seemed left out in communication, yet writing everything was so tiresome. Asked what they do during family conversations one parent responded:

It is particularly difficult for us during general family conversation such as during meal times or just family free time. It is impossible to write what everyone says. At such times a feeling of guilt sets in and I wish I had learnt sign language. (IP018) 
A few parents felt that it was not worth trying as sign language was impossible to learn and they were too old.

"I am too old for this kind of thing. I really try but I cannot understand how hands can move and make meaning. I just see it as a sort of miracle, you see, the working of a god." (IP09)

However, it was noteworthy that a few parents had learnt sign language with some success and were comfortable communicating with their children with HI. These parents confessed having had difficulties at the beginning but after learning a considerable amount of sign language have found working with a learner with $\mathrm{HI}$ manageable.

I must say I had problems when the child was younger. However, I purposed to learn the language my child would understand. With time I began to understand and communicate with some success. Right now I have no problem and I have made sure the whole of my family learn some signs. Am able to assist with assignments, carry out subject discussions and handle academic counseling comfortably. (IP022)

Results from interview with teachers revealed that some parents viewed the challenges of communicating in sign language with their children as issuing from the fact that some of the learners with HI had not mastered sign language completely. Parents who had learnt basic sign language realized they could not communicate with the learners effectively. Asked to explain the reason for this, parents explained that the learners acquired hearing impairment late and started off in regular primary schools where there were no specialist teachers. As a result, parents complained that the children were unable to express themselves effectively. The lack of a common mode of communication left the parents wondering whether the children's educational and emotional needs were met adequately.

"Some parents have learnt sign language, only to realize that the children they hoped to communicate with are themselves so poor in the language." (IT07)

According to the teachers, communication barrier was a major challenge parents faced in educating learners with HI. Most parents did not know sign language and therefore had challenges communicating with learners with HI. As a result, parents were not able to understand their children and the problems they faced. It was difficult for parents to discuss even the simplest concepts with learners with HI including issues on teenage challenges like relationships between boys and girls.

"Parents are missing out a lot in the development of their children. There are basic things children will learn from parents at home. If there is a breakdown in communication some stages of development pass unattended." (IT013)

Teachers stated that parents often relied on them to interpret when they came to the school to visit. Many times teachers risked getting very private information which a parent could discuss privately with the child if they had a common language.

"Of late, I avoid interpreting for parents unless in a meeting where I am sure only official information is

being passed on.”(IT03)

Results from interview with QUASO revealed that the office had regularly received complaints and accusations that the school and the ministry of education were not assisting parents in learning sign language. The QUASO observed that most of the communication challenges parents faced in educating learners with hearing impairments issued from lack of knowledge of sign language. The QUASO submitted that it was the parents to take the initiative to learn sign language and not blame the school or the ministry of education for their lack of knowledge.

"My office has sometimes liaised with the Educational Assessment and Resource Centre and organized trainings in basic sign language for parents but I encourage parents not to wait for such." (QUASO)

Results from parents' focus groups concurred with results from parents' and teachers' interviews on the view that lack of a common mode of communication with the children with HI denied parents the opportunity to communicate very basic issues. Parents in group one added that another major challenge parents faced was that whenever they gave instructions, it was either misinterpreted or misunderstood. This was a constant source of frustration for the parents. It also frustrated the children to learn that what they had done was different from what they were told to do. In addition, as a result of poor communication, the parents and siblings avoided assigning the learners with HI any work at home for fear that they might feel oppressed.

I usually avoid her when assigning duties in hurry and this makes her feel left out and ask why she is not assigned duty. It is a shame for me to explain to the child that I was in a hurry and couldn't write so I left her out. It is very confusing. My greatest fear in assigning duties is the risk of being misinterpreted. (PFG01)

Parents in group one also noted that there were communication challenges between them and their children with HI due to their poor or lack of knowledge in sign language. Consequently, parents felt left out in many aspects of their children's educational development and social life. They also expressed that the children were also left out of their lives causing parent/child disconnection. Many parents viewed sign language as difficult and impossible to learn in adulthood. A few however, felt that given the right forum, they would learn sign language well. Parents held that the school was not doing enough to assist them in developing a language of 
communication with learners. One parent raised concerns thus;

"I am invited to school a number of times for some other purposes and I come. If I am invited for a sign language workshop, I would gladly attend.... and I suggest you (the school) plan to give us certificates to give it weight." (PFG01)

Most parents in group two concurred with the views of parents in group one and added that lack of a common language of communication and not assigning the children duties were impacting negatively towards raising the whole child. Parents also stated that they felt frustrated when they did not understand what the children needed. The services of interpreters were not readily available and when they were, they were too costly for parents to afford.

"I want my child to grow up into an educated and responsible adult. However, most of the things she is supposed to learn must be signed yet my sign language is still poor. ” (PFG02)

Parents in group two also indicated that whenever they needed to communicate effectively to their child with HI or whenever they went with them to a function, they needed the services of an interpreter which most of them could not afford. As a result, they resorted to leaving the child at home even though they would have benefited from the proceedings at the meeting. The learners in their turn felt discriminated by the family and sometimes refused to cooperate in other activities.

Why would I leave her behind? Simple, I would rather she were not there than when she sits there and the rest of us are enjoying a speech and she keeps asking 'what?' and I cannot interpret. It is difficult I tell you. And then people are looking at you and wondering what the trouble is. I love my child, I want to go with her to all the interesting places but how on earth do I get her to enjoy these verbal things? (PFG02)

Most parents in group three said they had made efforts to learn sign language but did not learn much while others blamed their old age for their failure to learn a new language. Others just wondered how hands could move and make meaning. One parent explained;

I tried learning sign language but I could not go beyond the basic signs like greeting, asking, calling and saying 'Thank you'. I don't understand how someone can make a conversation using sign language though I really admire those who do. Their hands move so nicely. Maybe am too old. (PFG03)

Some parents in group three raised an additional area of challenge in communicating with learners with HI. Parents complained that before the learners came to secondary school they could communicate using Kiswahili (a Bantu language spoken as a first language among the Mijikenda tribes in the coastal region of Kenya, in Tanzania and a National language of the Kenyan people). However, after joining secondary school, the learners started using KSL and English more. Though the parents appreciated the fact that KSL was a subject and one of the languages of instruction, they felt deprived of the privilege to communicate comfortably with their children because they had not learnt KSL. The parents also complained about the fact that the HI did not do Kiswahili as a subject citing it as a disadvantage to the families. The parents noted that although the learners could still lip read and understand Kiswahili, they could no longer respond as fluently as before, causing a breakdown in communication. In the parents' view, the breakdown in communication between them and their children was worsened by the school and the education system.

"At home, Kiswahili is the language everyone uses. This English is a school thing but this child has forgotten how to communicate in Kiswahili as she used to." (PFG03)

Parents in group four raised two main issues in addition to those raised by other groups. The first one was a complaint that they found sign language so difficult because its structure was different from the spoken languages they were used to. The second challenge was lack of practice since learners with HI were in boarding school. Parents said that whenever learners with HI were at home, they practiced a lot but as soon as schools opened there was little chance for practice because there was an alternative mode of communication through speech. As a result, they would forget most of what they had learnt, making the learning process very slow and expensive.

"Apart from sign language being difficult to learn, as a family we have found it even more difficult to retain what we have learnt due to lack of practice when the child is away in school." (PFG04)

Results from teachers' focus group discussion revealed that a few parents were not interested in learning sign language. Teachers noted that since most of the learners had been HI for many years, any interested parent would have learnt the language. This was contrary to the view of most parents who complained that there were no training services, sign language was hard and that the school and the ministry were not assisting them. Teachers also stated that lack of proper communication many times led to misunderstandings between learners and their parents leading to unnecessary conflicts. Discipline was also a challenge as parents complained to teachers that they often lacked the language to correct learners with HI so their siblings often questioned why they would be punished while the learner with HI got away with many mistakes.

"Whenever some parents come to school they complain of not being able to communicate with the learners with HI, the learners being rude or uncooperative, having regular conflict and noticing learners' disinterest when they talk to them." (TFG) 
Another teacher had this to say about parents' inability to learn sign language;'

"I guess it's not a priority for many parents of the HI. Most parents don't want to make any effort. I think any parent who has had a child with HI close to five years should know some sign language irrespective of how he or she has learnt it."(TFG)

Teachers indicated that some parents were reluctant to take any step toward learning sign language. Instead, parents wanted that step made and paid for by some other people on their behalf.

Other parents said that since their efforts in learning sign language had not yielded much, they just talked to the learners with $\mathrm{HI}$ and the learners operated on guess work until they did the right thing.

"One parent said they used to have a problem communicating when the learner was younger but now when they talk the learner looks at the face and responds. They communicate this way though it keeps their conversation at official levels." (TFG)

Results from documents analyzed showed that parents often raised concerns on communication problems with their children with HI. Key among these concerns was the desire to learn and use sign language in order to get to understand their children better and assist in their education effectively. (Appendix 13)

From these findings, parents viewed communication challenges between them and their children with $\mathrm{HI}$ as being occasioned both by the school and the ministry of education. However, from the teachers' view, parents' own inability to learn, lack of interest and slow pace of learning the communication mode accessible to the learners were the main causes of the challenge. The findings of this study concur with a study by Scottish Government Publication (2005) which indicated that parents communication challenges was twofold: first, the children sometimes used signs that parents had not learned; secondly that children with HI missed out on activities because of lack of language and a communication code. Most parents, who stated they wanted to learn sign language, said it was mainly so that they could communicate with their children. This perspective is supported by a study carried out by Kimberly (2010) in the U.S.A which found out that the primary motivation for parents' for learning sign language was so that they would communicate with their children with HI.

The finding that most parents dismissed learning sign language on the grounds that it was hard or they were old implied that some parents of learners with HI did not seem to perceive the necessity to learn to develop their children's language so that they could communicate with their children as a priority by learning a language and communication mode accessible to learners with HI. However, it is also clear that the fact that the government had not fully fulfilled its mandate as stipulated in the Kenya Constitution (2010) on promoting the use of Kenyan Sign Language in public events could have contributed to the challenges parents were facing. This finding is negated by Gray (2011), who found out that language development is key in cognitive development. Gray emphasized that lack of language in early life delayed cognitive development.

\subsection{Communication between the parent and the school/teachers}

All the parents identified four major means of communication that existed between them and the school: newsletters, face to face, short message service (sms), the learners and occasional phone calls. Parents observed that the newsletters were a summary of many issues in the school term which were sometimes difficult to understand. Parents reported that learners were not well placed to explain.

"I receive newsletters from school at the end of the term but unless I go back to school and ask for clarification, there are points I don't understand. The children may not be able to explain because it is not meant for them." (IP021)

The short message services and the phone calls, they said, always came in occasionally and too late. Parents stated that whenever the messages or phone calls came, their programs were disorganized. Most parents from long distances found it difficult to respond to messages and phone calls that came in just one day before an important meeting. In addition, parents found it more challenging to respond if the message was a request for money which was not in the fee structure. Parents felt that if they got one to two weeks' notice, it would be possible to source funds, reorganize own program and attend.

"But, communication from the school to the parents has been a challenge. Information from the school sometimes comes so late that it is impossible to plan and attend. Teachers should plan well and inform us early." (IP019)

Parents raised concern over signed information given to learners to convey to parents. The challenge was that if the parent did not understand sign language, they would not receive the message at all. Parents felt that this made them miss out on some of the information that the school was trying to send across.

"Any signed information passed by the teachers through the learner is very difficult to get because it is difficult for me to understand what the learner is signing." (IP06).

Results from interview with teachers confirmed that teachers communicated to parents through the newsletters, short message service, phone calls, signed information through the learners and face to face verbal communication with parents. On newsletters, teachers concurred with parents that, parents did not respond well to issues raised in newsletters, indicating that there was a possibility that they did not understand the information 
contained in them.

"We rarely get adequate response to information passed to parents through school newsletters; in fact, most parents rarely remember receiving any from their children." (IT012)

The same case was with the communication through phone calls, short message service and signed information through learners. The teachers rated parents' response to the three means of communication as very low.

"Very few parents respond to information they get from the school through short message service, phone calls or learners." (IT06)

However, teachers observed that parents responded better to information delivered to them in a face to face encounter than all the other four means of communication. However, not many parents came to school to meet the teachers whenever they were required. As a result, communication between the school and parents was not very effective. One class teacher responded:

I have observed that we get more and better responses from parents over issues we have discussed face to face than any other type of communication. The worst or lowest responses are usually from information passed through short message service and through end term newsletters. We always urge parents to come to school for consultation on their children's education then we can discuss issues face to face. (IT01).

The results from interview with QUASO stated that he thought that communication between the school and parents was up to date as he had not received complaints from any parent. However, it was noted that parents' response to teacher/school communication was wanting.

"Parents need to pay regular visits to the school where their children are learning in order to meet with the teachers and know what is required. This is essential for the welfare of the learner." (QUASO).

Results from parents' focus group discussions revealed that most parents preferred to get information directly from the teachers in face to face encounters. However they found this a challenge because they were not able to come to school as regularly as they would have wished for various reasons.

"I prefer to get information from the teachers directly because then, I can ask questions and seek clarification of things I do not understand." (PFG01).

Parents in groups two, three and four concurred with group one. All parents in these groups stated that reading newsletters, short messages and receiving calls were good attempts but ineffective means of communication. If the school expected action, then it would be on information parents got from the teachers face to face. The following representative statement expresses the parents' views:

"It is not easy to respond to short messages and they are easily forgotten. As for phone calls, if they don't

come in good time, too bad. However, when we discuss something with the teacher, it stays with me." (TFG) In their focus group discussion, teachers confirmed the view of parents that there should be better planning and improved communication between the school and the parents. However, teachers noted that for most parents, lack of knowledge in sign language was mainly due to lack of interest rather than opportunities. One teacher revealed;

I have been teaching here for five years and I don't remember a single occasion when parents have been invited to school for any training in sign language. Many parents have made requests for such trainings but we have never been able to organize any. It could be lack of funds. (TFG)

Further, teachers confirmed parents' preference for face to face communication over all other means of communication that the school used.

Results from documents analysis revealed that during the annual general meeting, most parents considered communication challenge as a security threat to their children. Parents raised concerns about the learners with HI travelling alone saying people take advantage of the children being HI because they could not understand the spoken language. The minutes recorded the complaint raised by parents that their children often got into the wrong bus because touts just pushed them in.

Results from the parents' and teachers' interviews concur on the means used for communication and the ineffectiveness of the communication but differ on the reason for ineffectiveness. Whereas parents view the methods and timing of the school's communication as the cause of poor communication, teachers held that the main cause of ineffective communication was the parents' lack of interest. Since most parents were reported to respond better to face to face information, it implied that parents needed to come to school for the various activities where they would meet with the teacher. Parents considered the school disorganized while the school considered most parents not serious about their children's education. This contradiction maybe interpreted to mean that there may have been certain services learners missed because the school and the parents did not communicate with each other effectively. The findings of this study is negated by the findings of Lawson (2008) where parents were found to be highly motivated not to miss out on their children's communication needs.

Most parents agreed that the school made efforts to communicate to them but the communication methods were not effective. It is also clear that parents valued the information they got from the school concerning their children and their obligations. 
The finding of this study concurs with that of the Scottish Government Publication (2005) which submitted that parents complained that the school was not giving them enough information, giving information late and in a vague manner. Some parents also observed that communication with the teachers was not always easy.

It was also doubtful whether parents would receive signed information from school though their children. The study established that most parents of learners with HI did not know sign language and therefore were unlikely to receive any signed information. The implication for learners with HI would be missing out on important parental participation in their education. Lack of effective communication between the parents and the school could possibly lead to lack of essential services to learners with HI in school.

\subsection{Summary}

Most parents recognized that they could not communicate effectively with their children with HI because they had not learnt sign language and the deaf culture despite having raised children with HI for many years. While some parents held the view that they could not learn sign language at all saying it was too difficult, others held the view that they were too old to learn. Parents however indicated that they sometimes communicated with their children using gestures and speech which were not always effective. Many parents blamed the school and the government for not making services of learning sign language available to them.

This study also found out that the communication between parents and the school or teachers usually took the form of newsletters, short message service, telephone calls, learners and face to face encounters. Most parents indicated that the school and teachers did not communicate effectively with them most of the time. According to the parents they could not respond well to school communication because it either came too late or not at all. This study established that of all the methods used, only face to face encounter was effective but only for those who attended school functions. Newsletters, short message service, telephone calls and learners were not effective forms of communication between the parents and the school.

\section{Conclusion}

In view of the findings, this study concluded that;

Communication between parents and learners and between parents and the school were ineffective because; first, most parents lacked knowledge of sign language with some reasoning that sign language was too hard and some of them were too old to learn a new language. Secondly, parents viewed the school as disorganized in the way they communicated with parents. However, though parents preferred face to face communication, it was still ineffective because most parents rarely attended school functions where they could meet with the teachers. Consequently, most parents were not able to keep up with their children's development and educational needs due to challenges in communication.

\section{References}

Adoyo, PO 2004, Kenyan Sign Language and Simultaneous Communication: Differential Effects on Memory and Comprehension in Children with hearing impairments in Kenya. Kisumu: Lake Publishers and Enterprises.

Bertram, C \& Christiansen, IM 2013, Understanding research. An introduction to reading research. Retrieved fromhttps://www.efaqt.com/en/understanding-research-an-introduction-to-reading-research9780627031175

Braun, V \& Clarke, V 2006, Using Thematic Analysis. Qualitative Research (3) 77-101

Disability Development Partners (ddp) 2011, Report on deaf children in Burundi-their education and communication needs. London: Disability and Development Partners. Retrieved from http://ddpuk.org/deafchildren-burundi-report.pdf

Gray, J 2011, Why don't some hearing parents of deaf children use sign language? In American Annals of the Deaf, 135,211-215.

Kimberly, AW \& Thad, S 2010, We need to communicate! Helping parents of Deaf children Learn American sign language. Atlanta: Georgia Institute of Technology.

Kimu, M 2012, Parent involvement in public primary schools in Kenya. University of South Africa: Patterson

Lawson, AM 2008, Exploring the experiences of culturally Deaf parents who are raising hearing children. Dissertation. Graduate School of Gallaudet University.

Marschark, M. Bull, R., Sapere, P., Nordman, E., Skene, W., Lukomski, J. \& Lumsden, S 2012, Do you see what I see? School perspectives of deaf children, hearing children and their parents. European journal of special needs education. Retrieved from http://dx.doi.org/10.1080/08856257/2012.719106

McLeod, S 2008, Case study method. Retrieved from www.simplypsychology.org/casestudy.html

Republic of Kenya 2010, The constitution. Nairobi: Government Printers.

Rule, P \& John, V 2011, Your guide to case study research. ISBN 978030048. Retrieved from www.vanschaiknet.com 
Scottish Schools (Parental Involvement) Act 2006, Why should Parents be involved? Scottish Government Publication.

Yin, RK 2009, Case study research: Design and Methods. Thousand Oaks: Sage Publication

Yin, RK 2011, Qualitative research from start to finish, The Guilford Press. New York: Macmillan Publishing Co. Available at www.amazon.co/education-research-competencies-analysis-application

\section{Notes}

Key to codes:

The following are examples of codes used in the study to keep the identity of informants confidential:

IP01- interview with parent number one

IT(07)- interview with teacher number seven

PFG(02)- Parents' Focus Group two

TFG- Teachers' Focus Group 